\title{
Isotonic smooth muscle response in human bronchi exposed in vitro to nitrogen dioxide
}

\author{
P. Chitano*, R.E. Lucchini*, F. Calabrò**, M. Saetta*, P. Maestrelli*, \\ L.M. Fabbri+, C.E. Mapp*
}

Isotonic smooth muscle response in human bronchi exposed in vitro to nitrogen dioxide. P. Chitano, R.E. Lucchini, F. Calabrò, M. Saetta, P. Maestrelli, L.M. Fabbri, C.E. Mapp. CERS Journals Ltd 1996.

ABSTRACT: Exposure to nitrogen dioxide $\left(\mathrm{NO}_{2}\right)$, a common oxidant airborne pollutant, has been shown to cause reversible effects on lung function and airway responsiveness, in addition to airways inflammation. However, there have been conflicting reports concerning $\mathrm{NO}_{2}$-induced airway hyperresponsiveness. In the present study, we investigated the isotonic smooth muscle response in isolated human bronchi previously exposed in vitro to $\mathrm{NO}_{2}$.

Bronchial segments were obtained from 12 patients who had undergone thoracotomy for lung cancer. Bronchial segments from each patient were exposed to air and to 2.5 parts per million $(\mathrm{ppm}) \mathrm{NO}_{2}$ for $4 \mathrm{~h}$. The contractile response of bronchial rings to acetylcholine, neurokinin A (NKA), and substance $P$ was then studied under isotonic conditions. The response to NKA was also studied in rings, with or without epithelium, exposed either to air or $7 \mathrm{ppm} \mathrm{NO}_{2}$.

$\mathrm{No} \mathrm{NO}_{2}$-induced alteration of the bronchial smooth muscle isotonic response was found under any of the experimental conditions.

We conclude that in vitro exposure to up to $7 \mathrm{ppm}$ nitrogen dioxide does not cause alterations of the human bronchial smooth muscle shortening capacity. Eur Respir J., 1996, 9, 2294-2297.

\begin{abstract}
*Institute of Occupational Medicine, and **Dept of Thoracic Surgery, University of Padua, Padua, Italy. +Institute of Infectious and Respiratory Diseases, University of Ferrara, Ferrara, Italy.
\end{abstract}

Correspondence: C.E. Mapp

Istituto di Medicina del Lavoro

Via J. Facciolati, 71

35127 Padova

Italy

Keywords: Air pollution

airway smooth muscle

asthma

oxidants

Received: December 281995

Accepted after revision July 251996

This work was funded in part by the NRCENEL Project-Interactions of Energy Systems with Human Health and Environment Roma, NRC (FATMA 91.00150.PF41 and 92.00233.PF41, Bilateral Project FranceItaly 96.00100.CT04), Italian Ministry of Education, European Commission (Biomedical and Health Research Program BMH 1, CT 94 - 1281), and A.S.T.M.P. Padova.
Nitrogen dioxide $\left(\mathrm{NO}_{2}\right)$ is one of the most common oxidant airborne pollutants, and is produced by processes involving high temperatures. Standard limits of exposure are recommended in most countries relating both to the general environment $(0.21$ parts per million (ppm) for $1 \mathrm{~h}$ exposure for the World Health Organization (WHO) Europe guidelines) and occupational exposures (2-5 ppm time-weighted average and 5-10 ppm short-term exposure limit) $[1,2]$.

Several experimental and epidemiological studies have shown that $\mathrm{NO}_{2}$ causes alterations of lung function and increases airway responsiveness. However, conflicting results have been reported, which makes it difficult to clarify the mechanisms leading to these $\mathrm{NO}_{2}$ effects [3, 4].

Whether the in vivo effects on pulmonary function and airway responsiveness involve alterations of bronchial smooth muscle responsiveness has not yet been elucidated. For this reason, we have recently investigated the smooth muscle response in isolated bronchi from rats exposed in vivo to $10 \mathrm{ppm} \mathrm{NO}_{2}$ [5], as well as in guinea-pig bronchi exposed in vitro to up to $10 \mathrm{ppm}$ $\mathrm{NO}_{2}[6,7]$. In the latter studies, we could not demon- strate any alteration of the smooth muscle response induced by $\mathrm{NO}_{2}$.

To our knowledge, only one study has been carried out in an attempt to characterize the effect of $\mathrm{NO}_{2}$ on isolated human bronchial smooth muscle [8]. In that study, an increased responsiveness to carbachol, histamine, and substance P (SP) was observed under isometric conditions after a $30 \mathrm{~min}$ in vitro exposure to $2 \mathrm{ppm} \mathrm{NO}$. Experimental conditions which induce alterations of airway smooth muscle responsiveness have shown that force development (isometric measurements) and shortening capacity (isotonic measurements) may be differentially affected, e.g. an increased shortening capacity has been reported after in vitro treatment of human airway smooth muscle with collagenase [9], as well as after in vivo sensitization of dogs to ragweed antigen [10], with little or no effect on isometric force generation. Therefore, in the present paper, we investigated the in vitro response of human bronchial smooth muscle under isotonic conditions. In order to evaluate the influence of the epithelium on a possible alteration of the response, we also performed the present study on bronchial rings without epithelium. 


\section{Material and methods}

Human lung tissue was obtained from 12 patients, 8 males and 4 females, aged $63 \pm 3$ (mean \pm SEM) yrs, who had recently undergone thoracotomy for lung cancer. All patients had a lung function test before surgery, that included vital capacity and forced expiratory volume in one second.

Ten to thirty minutes after surgical resection, a macroscopically normal part of the resected tissue was immersed in ice-cold oxygenated Krebs-Henseleit, solution containing the following (mM): $\mathrm{NaCl} 118.3 ; \mathrm{KCl} 4.7$; $\mathrm{MgSO}_{4} 1.2 ; \mathrm{H}_{2} \mathrm{PO}_{4} 1.2 ; \mathrm{NaHCO}_{3} 25.0 ; \mathrm{CaCl}_{2} 2.5$; and $\mathrm{D}(+)$-glucose 11.1. Bronchial segments (about $4 \mathrm{~cm}$ in length) were dissected free of loose connective tissue, under a stereomicroscope Technival 2 (Jena). The tissue was kept in fresh aerated buffer throughout the dissection procedure.

\section{Exposure to nitrogen dioxide}

Two bronchial segments from each patient were cannulated at their proximal end with Teflon tubes connected to gas cylinders. One was exposed to air and the other to $\mathrm{NO}_{2}$ in air, while immersed in KrebsHenseleit solution at room temperature, as reported previously for guinea-pig main bronchi $[6,7]$. Both air and $\mathrm{NO}_{2}$ in air were used dry, since humidification could produce nitrous and nitric acids before entering the bronchi, because of the high reactivity of $\mathrm{NO}_{2}$. A constant intraluminal flow of $1 \mathrm{~mL} \cdot \mathrm{s}^{-1}$ for $4 \mathrm{~h}$ was used, since previous studies have shown that, with this modality, flow and time of exposure, dry air does not alter smooth muscle contractility to different agonists, when compared with tissue maintained unexposed in KrebsHenseleit solution [7]. A similar method of in vitro exposure with $50 \mathrm{~mL} \cdot \mathrm{s}^{-1}$ of airflow for $30 \mathrm{~min}$ (using dry air) has been shown not to produce any adverse effects on human airway smooth muscle contractility in response to different agonists, when compared with tissue maintained unexposed in Krebs-Henseleit solution [8]. Exposure to $\mathrm{NO}_{2}$ was carried out at either 2.5 ppm (tissue obtained from five patients) or 7 ppm (tissue obtained from seven patients). These two concentrations of $\mathrm{NO}_{2}$ were chosen because they are slightly above present recommended occupational exposure limits, and they actually represent levels often reached for short periods in the workplace.

\section{In vitro study}

After the exposure, rings (inner diameter of 2.5-3 $\mathrm{mm}$ ) were prepared from the portion of each bronchus which had not been cannulated (about $3 \mathrm{~cm}$ in length). The length of each ring was $2-3 \mathrm{~mm}$, so that several rings could be obtained from each segment. Rings were mounted in a double-jacketed organ bath filled with Krebs-Henseleit solution at $37^{\circ} \mathrm{C}$, and continuously aerated with a $95 \% \mathrm{O}_{2}$ and $5 \% \mathrm{CO}_{2}$ gas mixture, which produced a $\mathrm{pH}$ of 7.4. The bronchial rings were connected to isotonic transducers (Basile, Mod. 7006) for continuous recording of length changes. The rings were then allowed to equilibrate for $90 \mathrm{~min}$ and resting tension was adjusted to $500 \mathrm{mg}$, which we had previously found kept this preparation close to its optimal length (Lo) and allowed for maximal response. The average values of Lo were $3.54 \pm 1.02$ and $3.67 \pm 1.14 \mathrm{~mm}$ for airand $\mathrm{NO}_{2}$-exposed rings, respectively. During the equilibration period, which averaged $1.5 \mathrm{~h}$, the bronchial rings were washed with fresh Krebs-Henseleit solution every $20 \mathrm{~min}$. The responses were recorded on a Battaglia Rangoni model K380 polygraph recorder (Bologna, Italy). After the equilibration period, $0.1 \mathrm{mM}$ acetylcholine (ACh) was administered and the response was monitored. Preparations which did not respond to acetylcholine were rejected. The bronchial rings were then rinsed until they returned to their Lo value.

\section{Experimental protocols}

In a first set of experiments, rings were exposed to $2.5 \mathrm{ppm} \mathrm{NO}_{2}$ or air for $4 \mathrm{~h}$. After the repeated washing, when the bronchial ring length was stable, concentration-response tests to either ACh $\left(10^{-9}-10^{-3} \mathrm{M}\right)$, neurokinin A (NKA) $\left(10^{-11}-10^{-5} \mathrm{M}\right)$, or substance P (SP) $\left(10^{-9}-10^{-4} \mathrm{M}\right)$ were performed.

In a second set of experiments, rings exposed to 7 ppm $\mathrm{NO}_{2}$ or air for $4 \mathrm{~h}$ were studied and concentrationresponse tests to NKA were performed. $\left(10^{-11}-10^{-5} \mathrm{M}\right)$. This study was conducted both in rings with intact epithelium and rings in which the epithelium had been removed by gently rubbing the luminal surface of the bronchial segments with a gauze, immediately before the exposure.

\section{Drugs and chemicals}

Acetylcholine and neurokinin A were obtained from Sigma Chemical Co. (St Louis, MO, USA); substance $\mathrm{P}$ from Peninsula Laboratories (St Helens, UK); cylinders containing 2.5 or $7 \mathrm{ppm} \mathrm{NO}_{2}$ stabilized in air were obtained from SIAD (Camin, Padua, Italy).

\section{Analysis}

Values are given as mean \pm SEM. The smooth muscle responses (shortening) were expressed as a percentage of the ring length.

Comparisons were performed by analysis of variance (ANOVA) for repeated measures and by a two-tailed Student's t-test using the StatView II statistical package (Abacus Concepts, Inc., Berkeley, CA, USA). A pvalue of less than 0.05 was considered significant.

\section{Results}

The concentration-response curves to ACh, NKA, and $\mathrm{SP}$ in bronchi exposed to air or $2.5 \mathrm{ppm}$ of $\mathrm{NO}_{2}$ are shown in figure 1. No significant difference was found between shortening developed by rings exposed to air and to $2.5 \mathrm{ppm}$ of $\mathrm{NO}_{2}$. 

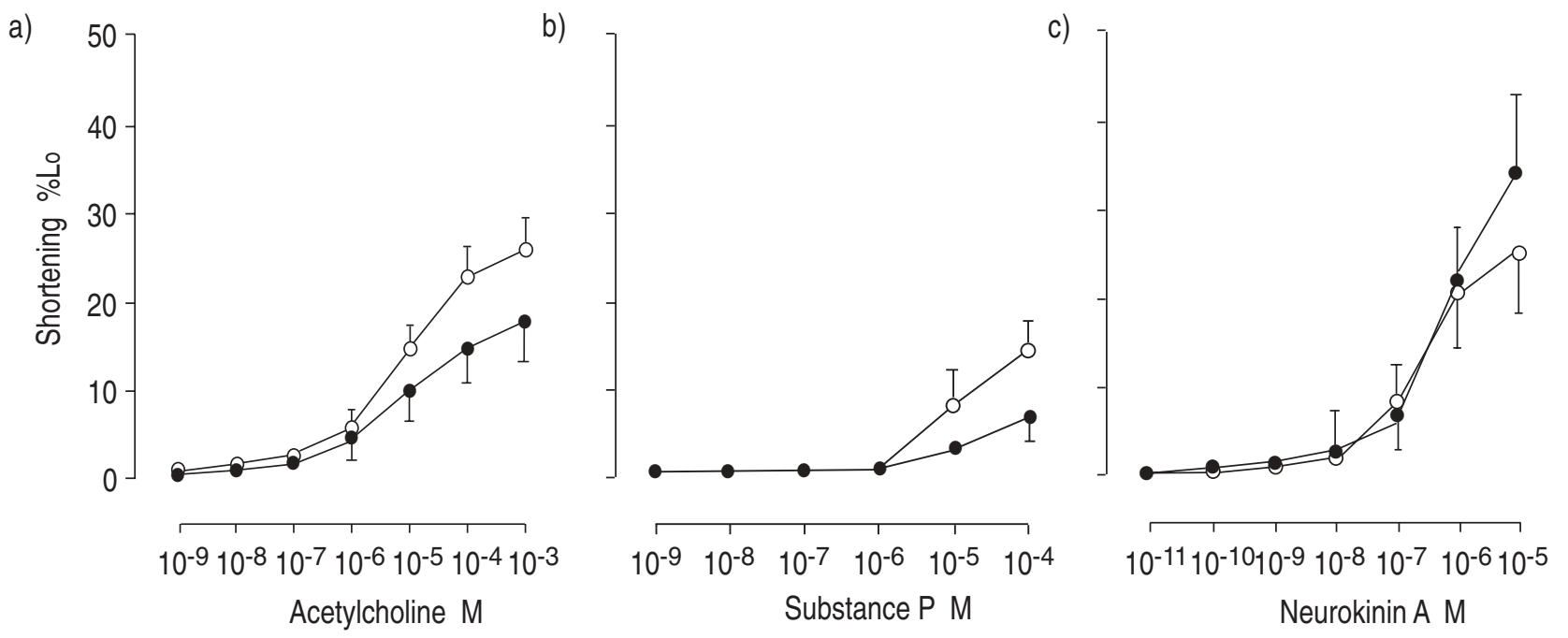

Fig. 1. - Concentration-response curves to: a) acetylcholine (ACh); b) substance P (SP); and c) neurokinin A (NKA) in human bronchi exposed for $4 \mathrm{~h}$ to air (-O-) or $2.5 \mathrm{ppm}$ of nitrogen dioxide (- - Each point is mean \pm SEM; the number of rings exposed to air and nitrogen dioxide were, respectively: $n=7$ and $n=8$ for $A C h ; n=5$ and $n=6$ for SP; and $n=4$ and $n=4$ for NKA; Lo: optimal length. No significant difference was found by analysis of variance (ANOVA) $(\mathrm{F}=1.62 ; \mathrm{p}=0.23$ for $\mathrm{ACh} ; \mathrm{F}=2.80 ; \mathrm{p}=0.13$ for $\mathrm{SP}$; and $\mathrm{F}=0.27$; $\mathrm{p}=0.65$ for $\mathrm{NKA}$ ).

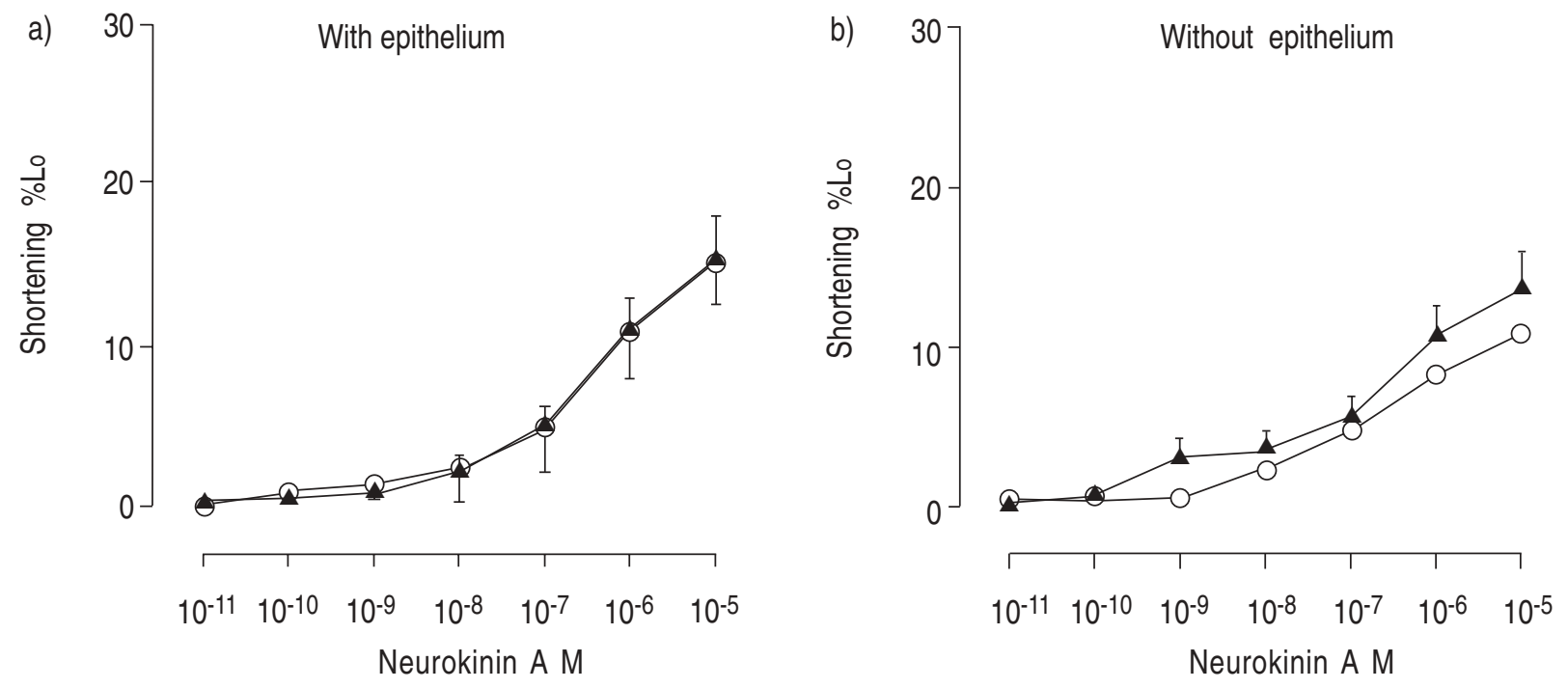

Fig. 2. - Concentration response curves to neurokinin A in human bronchi: a) with; and b) without epithelium, exposed for 4 h to air (- - ) or $7 \mathrm{ppm}$ of nitrogen dioxide (- - E ). Each point is mean \pm sEM; the number of rings exposed to air and nitrogen dioxide were, respectively, $\mathrm{n}=6$ and $n=6$ for bronchi with epithelium and $n=8$ and $n=5$ for bronchi without epithelium; Lo: optimal length. No significant difference was found by analysis of variance (ANOVA) ( $\mathrm{F}=0.002 ; \mathrm{p}=0.97$ for bronchi with epithelium; and $\mathrm{F}=0.62$; $\mathrm{p}=0.45$ for bronchi without epithelium).

The bronchial smooth muscle response to NKA after exposure to air or 7 ppm $\mathrm{NO}_{2}$ also showed no significant difference, both in tissue with and without epithelium. Figure 2 shows the concentration-response curves to NKA obtained from rings of bronchi exposed to air or 7 ppm $\mathrm{NO}_{2}$ with (fig. 2a) and without epithelium (fig. 2b).

The values of sensitivity to each contractile agent were estimated as the concentration which produced $50 \%$ of the response to the highest agonist concentration (EC50). No difference was observed in EC50 for $\mathrm{ACh}, \mathrm{NKA}$ and SP between $\mathrm{NO}_{2}$-exposed and control rings.

\section{Discussion}

In the present study, we investigated human bronchial smooth muscle response in rings obtained from bronchial segments exposed in vitro to either 2.5 or $7 \mathrm{ppm} \mathrm{NO}_{2}$. Bronchi, with and without epithelium, were used in a series of experiments. Under all experimental conditions, we found no $\mathrm{NO}_{2}$-induced alteration of the airway smooth muscle response to the stimuli employed.

In vivo airway hyperresponsiveness induced by $\mathrm{NO}_{2}$ in humans has been demonstrated in several studies, though not always reproduced successfully. Furthermore, in some of the studies which reported a reduced lung function or increased responsiveness, only a proportion of the subjects developed symptoms. To explain these discrepancies, it has been suggested that differences in susceptibility might exist between subjects, and hence a group of responders and a group of nonresponders, [4].

Airway hyperresponsiveness observed in vivo may be the result of an alteration of the smooth muscle contractility itself (demonstrable in vitro) as well as of a 
modification of one or more factors, e.g. secretions, inflammation, neural reflexes, or parenchymal elastic recoil, which affect smooth muscle response in vivo but not in vitro. With the aim of studying the effect of $\mathrm{NO}_{2}$ on smooth muscle contractility, we have recently investigated, in vitro, bronchial rings from animals and from isolated bronchi exposed to up to $10 \mathrm{ppm} \mathrm{NO}_{2}$ and found no $\mathrm{NO}_{2}$-induced alteration [5-7]. By contrast, the only study which analysed human bronchi exposed in vitro to $\mathrm{NO}_{2}(2 \mathrm{ppm})$ has shown an increased bronchial smooth muscle responsiveness [8]. Since the present paper cannot confirm the latter results, the hypothesis of the presence of responders and nonresponders suggested for the different in vivo observations seems to be applicable, likewise, in the case of in vitro exposures.

Furthermore, it is important to point out that the smooth muscle response was analysed under different experimental conditions (isometric in the study by BENJEBRIA et al. [8] and isotonic in the present study). The alteration of smooth muscle responsiveness may consist of a change in the ability to produce force, or in the shortening capacity, or in both. Whilst the reduction or augmentation of force production would be dependent on the number of contractile elements in the cross-section of the preparation, an alteration of the shortening capacity would be due to changes in either the viscoelastic or the biochemical properties of the smooth muscle, such as cytoskeletal protein stiffness or myofibrillar adenosine triphosphatase (ATPase) activity [10]. In this respect, since an increased responsiveness was only observed under isometric conditions, $\mathrm{NO}_{2}$ exposure would cause an increased number of cross-bridges to form and cycle upon stimulation.

In the present study, we also investigated the smooth muscle response in rings with and without epithelium exposed to either air or $7 \mathrm{ppm} \mathrm{NO}_{2}$. Indeed, a strong influence may be exerted by airway epithelium on smooth muscle contractility, possibly through the release of nitric oxide. Furthermore, exposure to $\mathrm{NO}_{2}$ has been shown to affect epithelial permeability and to damage epithelial cells $[3,4]$. However, we found no differences between bronchi with and without epithelium, so no definite conclusion could be reached.

Exposure to $\mathrm{NO}_{2}$ has also been demonstrated to consistently cause airway inflammation $[3,4]$. A cause-effect link between inflammation and bronchial hyperresponsiveness has never been definitely demonstrated; however, inflammatory mediators may trigger or potentiate smooth muscle hyperresponsiveness. The present study suggests that $\mathrm{NO}_{2}$ does not directly cause an increase of bronchial smooth muscle responsiveness, but we cannot exclude that inflammation or delayed effects may occur when animals are exposed in vivo. Therefore, the possibility that $\mathrm{NO}_{2}$-induced airway hyperresponsiveness is secondary to induction of an inflammatory response needs to be confirmed by studies with exposure to $\mathrm{NO}_{2}$ in vivo.

In conclusion, the present study suggests that a $4 \mathrm{~h}$ in vitro exposure to up to $7 \mathrm{ppm}$ nitrogen dioxide does not cause alterations of the human bronchial isotonic smooth muscle responsiveness. Because of the controversial results reported in the literature in studies employing several different approaches, we believe that further investigation will require more emphasis on dose-related effects of this oxidant pollutant.

Acknowledgements: The authors wish to thank S. Milanetto for technical assistance.

\section{References}

1. World Health Organization. Air quality guidelines for Europe. Copenhagen, Denmark, WHO Regional Publications, European Series No. 23, 1987.

2. International Labour Organization. Occupational exposure limits for airborne toxic substances. Occupational safety and health series, No. 37, Geneva, International Labour Office, 1991.

3. Chitano P, Hosselet JJ, Mapp CE, Fabbri LM. Effect of oxidant air pollutants on the respiratory system: insights from experimental animal research. Eur Respir $J$ 1995; 8: 1357-1371.

4. Sandström T. Respiratory effects of air pollutants: experimental studies on humans. Eur Respir J 1995; 8: 976-995.

5. Chitano P, Boniotti A, Papi A, et al. Effect of subchronic in vivo exposure to nitrogen dioxide on lung tissue inflammation, airway microvascular leakage, and in vitro bronchial smooth muscle responsiveness in rats. Occup Environ Med 1996; 53: 379-386.

6. Chitano $\mathrm{P}$, Lucchini RE, Coser $\mathrm{E}$ et al. In vitro exposure of guinea pig main bronchi to $2.5 \mathrm{ppm}$ of nitrogen dioxide does not alter airway smooth muscle response. Respir Med 1995; 89: 323-328.

7. Chitano $\mathrm{P}$, Coser E, Lucchini RE et al. In vitro exposure to nitrogen dioxide $\left(\mathrm{NO}_{2}\right)$ does not alter bronchial smooth muscle responsiveness in ovalbumin-sensitized guinea-pigs. Pulm Pharmacol 1994; 7: 251-257.

8. Ben-Jebria A, Marthan R, Savineau JP. Effect of in vitro nitrogen dioxide exposure on human bronchial smooth muscle response. Am Rev Respir Dis 1992; 146: 378-382.

9. Bramley AM, Roberts CR, Schellenberg RR. Collagenase increases shortening of human bronchial smooth muscle in vitro. Am J Respir Crit Care Med 1995; 152: 1513-1517.

10. Stephens NL. Postjunctional factors in airway smooth muscle hyperresponsiveness. In: Fishman AP, Macklem PT, Mead J, Geiger SR, eds. Handbook of Physiology: The Respiratory System. III. Baltimore, Maryland, USA, American Physiological Society, 1986; pp. 719-726. 